\title{
CORRIGENDUM
}

\section{ON SOME EXTENSIONS OF HARDY'S INEQUALITY}

\section{CHRISTOPHER O. IMORU}

Department of Mathematics

University of Ife

Ile-Ife, Nigeria

Ther:: are some misprints in the above paper (which appeared in Vol. 8 , No. 1, 1985, pp 165-171). The'se errors are corrected as follows:

On p. 165, line 5 up: "1-r" should read $1-r$.

On p. 165, line 4 up: in should read if.

On p. 156, line 10: $\frac{b}{0}$ in (1.2) and ${ }_{a}^{\infty}$ in (1.3) are replaced by

$$
\mathrm{b} \text { should read } \int_{0}^{b} \text { in (1.2) and } \int_{a}^{\infty} \text { in (1.3) are replaced by } \int_{a}^{b} \text {. }
$$

On p. 166, line 3 of Theorem 2.1: The integral signs are omitted.

On p. 167, line 8: $[g(c)=g(d)]$ should read $[g(c), g(d)]$.

On p. 167, line 10: $G(x)$ should read $F(x)$.

On p. 167, line 11: $\sigma,(g(b))$ should read $v(g(b))$.

On p. 167, line 20: uncer should read under.

on p. 168, line 1: $h(t)$ should read $h(\underline{t})$.

On p. 168, Line 4: $\left.\ldots \int_{c^{*}}^{\hat{A}^{*}} h(\underline{t})^{1 / p} d \lambda(t)\right]^{p}$ should read $\left.\ldots \int_{c^{*}}^{x^{*}} h(t)^{1 / p} d \lambda(\underline{t})\right]^{p}$.

On p. 168, Line 9 11p: $p>0$ should read $p<0$.

On p. 168, line 1?: $\ldots \sum_{i=1}^{i} q_{i}(1 \leqslant v \leqslant n)$ should read $\ldots \sum_{i=1}^{n} q_{i}(1 \leqslant v \leqslant n)$.

On P. 168, Line 1\%: $\left.\ldots \int_{y^{*}}^{y^{*}} d \lambda(\underline{t})\right]^{p}$ should read $\left.\ldots \int_{y^{*}}^{x^{*}} d \lambda(\underline{t})\right\}^{p}$.

On P. 168, line 1 up: $\ldots .9 Q(:, F) \ldots$ should read $\ldots ., Q(\cdot, 0, F) \ldots$

On p. 169, line $3:$....... should read ...or....

On p. 169, line 4: $Q(x, \varepsilon, F)=1)$ should read $Q(x, 0, F)>0$.

On p. 169, line 7: Insert the integral sign.

On p. 170, line 7 ap: Number the integral by adding (4.4) on the right.

On p. 170, line 6 up: $\sigma_{0}(x) g(x)^{-r} g^{\prime}(x)$ should read $\sigma_{0}(x)=g(x)^{-r} g^{\prime}(x)$. 


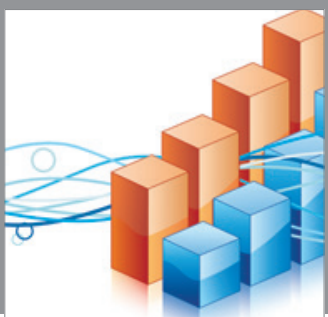

Advances in

Operations Research

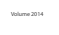

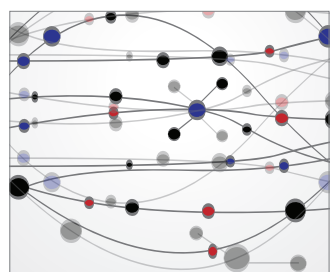

\section{The Scientific} World Journal
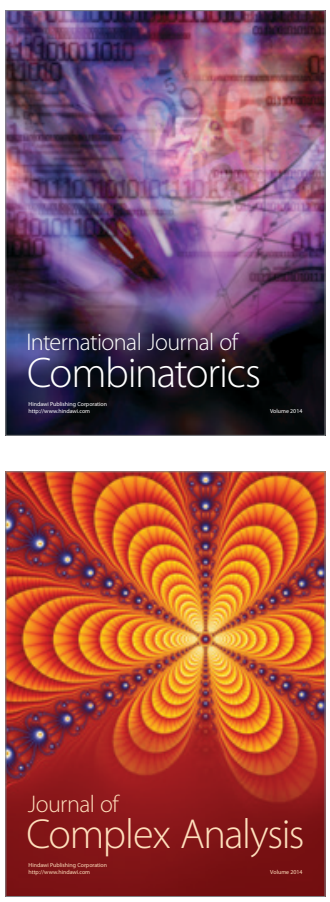

International Journal of

Mathematics and

Mathematical

Sciences
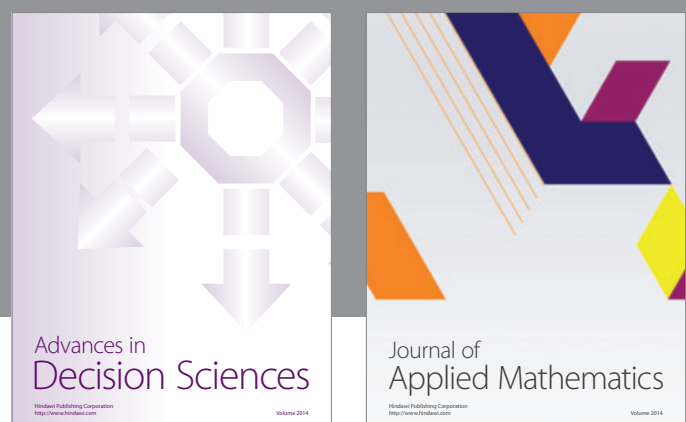

Journal of

Applied Mathematics
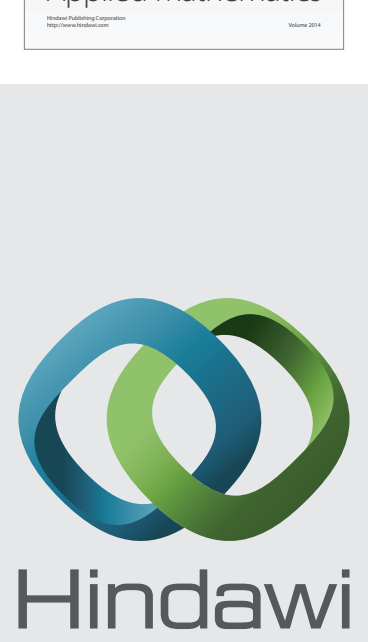

Submit your manuscripts at http://www.hindawi.com
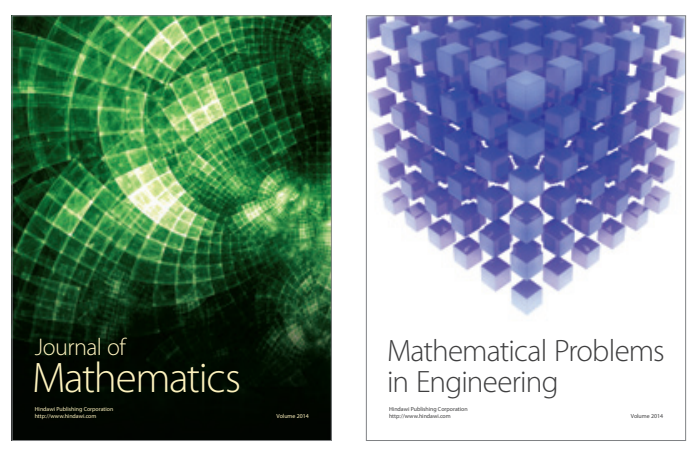

Mathematical Problems in Engineering
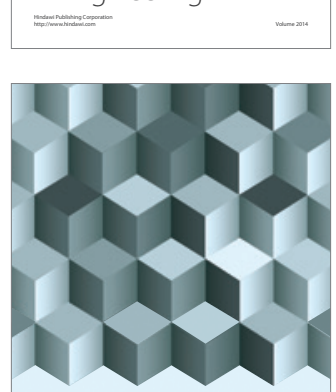

Journal of

Function Spaces
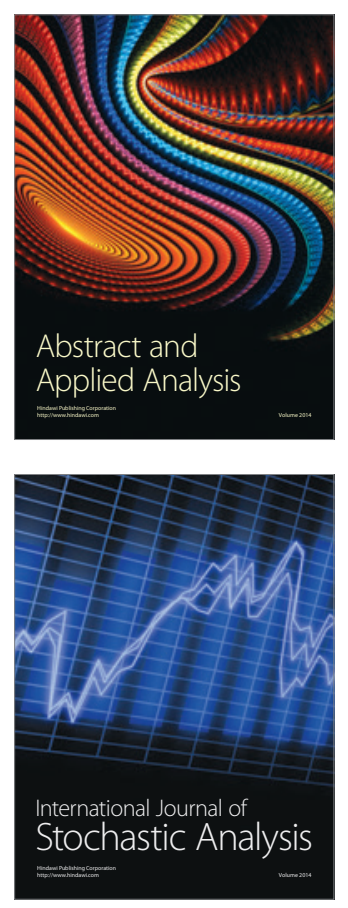

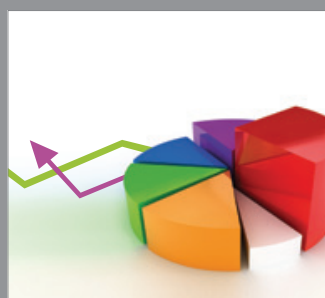

ournal of

Probability and Statistics

Promensencen
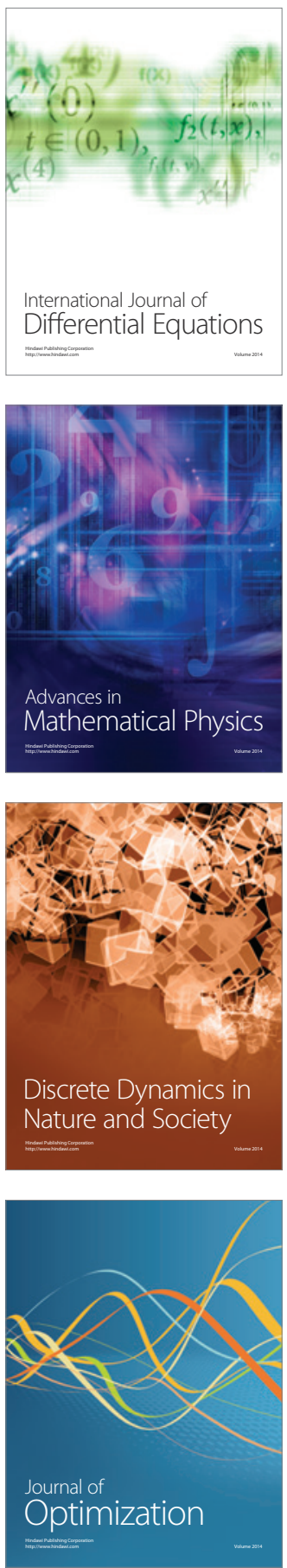